\title{
Retention Strategies for Health Disparities Preventive Trials: Findings from the Early Childhood Caries Collaborating Centers
}

\author{
Raul I. Garcia, DMD, MMedSc ${ }^{a}$, Tamanna Tiwari, BDS, MDS, MPH ${ }^{b}$, Francisco Ramos- \\ Gomez, DDS, MS, MPH ${ }^{\mathrm{c}, \mathrm{d}}$, Brenda Heaton, MPH, PhD ${ }^{\mathrm{a}}$, Mario Orozco, DDS, MPH, MBA ${ }^{\mathrm{d}}$, \\ Margaret Rasmussen, MPH ${ }^{\mathrm{d}}$, Patricia Braun, MD, MPH ${ }^{\mathrm{b}}$, Michelle Henshaw, DDS, MPH ${ }^{\mathrm{a}}$, \\ Belinda Borrelli, $\mathrm{PhD}^{\mathrm{a}}$, Judith Albino, $\mathrm{PhD}^{\mathrm{b}}$, Clemencia Vargas, DDS, $\mathrm{PhD}^{\mathrm{e}}$, Courtney \\ Diamond, BS ${ }^{a}$, Christina Gebel, MPH ${ }^{\mathrm{a}}$, Terrence S. Batliner, DDS, MBA ${ }^{\mathrm{b}}$, Judith Barker, \\ PhD $^{d}$, Steven Gregorich, PhD ${ }^{d, f}$, Stuart A. Gansky, DrPH ${ }^{d}$, and The Early Childhood Caries \\ Collaborating Centers
}

${ }^{a}$ Center for Research to Evaluate and Eliminate Dental Disparities (CREEDD), Boston University Henry M. Goldman School of Dental Medicine, Boston, Massachusetts ${ }^{b}$ Center for Native Oral Health Research (CNOHR), University of Colorado Anschutz Medical Campus, Aurora, Colorado 'School of Dentistry, University of California Los Angeles, Los Angeles, California ${ }^{\mathrm{d} C e n t e r ~ t o ~}$ Address Disparities in Children's Oral Health (CAN DO), School of Dentistry, University of California San Francisco, San Francisco, California e Division of Pediatric Dentistry, University of Maryland School of Dentistry, Baltimore, Maryland ${ }^{\mathrm{f} D e p a r t m e n t ~ o f ~ M e d i c i n e, ~ S c h o o l ~ o f ~ M e d i c i n e, ~}$ University of California, San Francisco

\section{Abstract}

Objectives-To identify successful strategies for retention of participants in multi-year, community-based randomized controlled trials (RCTs) aiming to reduce early childhood caries in health disparities populations from diverse racial/ethnic backgrounds and across diverse geographic settings.

Methods-Four RCTs conducted by the Early Childhood Caries Collaborating Centers (EC4), an initiative of the National Institute of Dental and Craniofacial Research, systematically collected information on the success of various strategies implemented to promote participant retention in each RCT. The observational findings from this case series of four RCTs were tabulated and the strategies rated by study staff.

Results-Participant retention at 12 months of follow-up ranged from $52.8 \%$ to $91.7 \%$, and at 24 months ranged from $53.6 \%$ to 85.9 , across the four RCT. For the three RCT that had a 36 month follow-up, retention ranged from $53.6 \%$ to $85.1 \%$. Effectiveness of different participant retention strategies varied widely across the RCT.

Corresponding author: Dr. Raul Garcia, Department of Health Policy and Health Services Research, Boston University Henry M. Goldman School of Dental Medicine, 560 Harrison Avenue, Boston, MA 02118, [ rig@ bu.edu], 617-638-6385.

The authors had no financial or other relationships that might lead to a conflict of interest in the work reported. 
Conclusions-Findings from this case series study may help to guide the design of future RCTs to maximize retention of study participants and yield needed data on effective interventions to reduce oral health disparities.

\section{Keywords}

health status disparities; minority groups; randomized controlled trials; refusal to participate; dental caries; child; participant retention; attrition

\section{Introduction}

Over the past two decades, the field of oral health disparities research has advanced from observational studies aimed at understanding the causes and consequences of oral health disparities to theory-based interventions aimed at reducing and eliminating disparities. In 2008, the National Institute of Dental and Craniofacial Research (NIDCR), a component of the US National Institutes of Health, funded a consortium of collaborating research centers to conduct community-based caries prevention clinical trials, each using a 'hard' clinical outcome, aimed at reducing early childhood caries (ECC) over a two- to three-year followup period. Four separate randomized controlled trials (RCTs), each working with underserved populations that have been disproportionately burdened by ECC, were conducted under the auspices of the Early Childhood Caries Collaborating Centers (EC4).

The EC4 is comprised of three separately funded research centers - the Center for Native Oral Health Research (CNOHR), University of Colorado Anschutz Medical Campus, Aurora, CO; the Center to Address Disparities in Children's Oral Health (known as CAN DO), School of Dentistry, University of California San Francisco, San Francisco, CA; and the Northeast Center for Research to Evaluate and Eliminate Dental Disparities (CREEDD), Boston University Henry M. Goldman School of Dental Medicine, Boston, MA; all three supported by a single Data Coordinating Center (DCC), based at the University of California San Francisco. The community contexts for the RCTs include urban public housing developments (CREEDD), primarily Hispanic communities near the US-Mexican border (CAN DO), and rural American Indian reservation areas (CNOHR). These communities have a high prevalence of ECC and are most likely to benefit from the identification of effective, sustainable and culturally acceptable interventions.

Recruitment and retention of participants from such populations is recognized to be challenging. ${ }^{1,2}$ Socioeconomic characteristics may influence the rates of retention, with participants of lower socioeconomic status finding participation intrusive or burdensome. ${ }^{3}$ Retention of hard-to-reach participants has been a longtime topic of interest, particularly when pertaining to clinical interventions for conditions that require recurring outpatient appointments and consistent follow-up, such as $\mathrm{HIV}^{4}$, $\mathrm{PTSD}^{5}$, depression ${ }^{6}$, and ADHD. ${ }^{7}$ Moreover, research integrity may suffer if RCTs fail to adequately include and retain hardto-reach populations, leading to decreased generalizability or validity of findings. ${ }^{8}$ Not overcoming challenges to retention may also contribute to underrepresenting or excluding minorities from research. ${ }^{9}$ 
The EC4 has earlier reported on recruitment strategies used ${ }^{10}$ to enroll over 4,000 participants across four RCTs. Similarly challenging is the retention of enrolled participants over an RCT's multi-year duration, necessary to assess a hard clinical outcome such as ECC prevention. Trials may fail to yield valid results due to reduced power from significant overall attrition, or to differential attrition between RCT arms. Adequate retention is thus recognized to be essential to an RCT's success, in regard to its internal validity as well as to its external validity and thus the generalizability of findings to the communities of interest.

Despite the continuing need for, and support of, community-based intervention studies to address oral health disparities, there is a surprising paucity of information in the peerreviewed literature on successful participant retention strategies for clinical trials in oral health disparities populations. With the continuing need to rigorously test interventions to reduce oral health disparities, the findings reported here should be of value to other investigators planning work in this important area of research. The recruitment and retention of minority populations in clinical and community-based research, particularly that focusing on reducing health disparities, remain challenging tasks. While none of the EC4 RCTs formally tested and compared different retention strategies, as such work was beyond the focused scope of each study, the observations made by each study and their 'lessons learned' may nevertheless be useful in guiding the design of future RCTs. In addition, our findings may serve to identify promising research questions for systematic investigation. Assessing different retention strategies in oral health disparities intervention studies may be viewed as a worthy research aim in itself, and may serve to further our understanding of how to effectively reduce and eliminate oral health disparities.

\section{Methods}

\section{Study participants and data sources}

Data were obtained on participant attendance at scheduled study follow-up visits within the four separate RCTs, for up to three years of follow-up depending on the study. The participating EC4 research centers, their principal investigators, and their RCTs are listed in Table 1. A single Data Coordinating Center (DCC), based at the University of California, San Francisco, was established to serve the EC4 RCTs, and the NIDCR constituted a single Data and Safety Monitoring Board to oversee all the trials. The DCC compiled data on participant retention for the four RCTs. Each RCT's staff compiled its narrative experiences in implementing various retention strategies and reported them to an EC4 Working Group (WG) on Recruitment and Retention. The Recruitment and Retention WG members represented each RCT on regularly scheduled teleconferences to share information based on their experiences and lessons learned, discuss common problems, and explore innovations on participant recruitment and retention. Each RCT received approval for its protocol from the NIDCR and from each funded center's Institutional Review Board(s). In addition, each of the two RCTs working with American Indian groups received approval from the relevant tribal review boards.

The CNOHR Study I is aimed at assessing the efficacy of a Motivational Interviewing intervention to prevent caries in children through knowledge and behavior change in AI mothers in a Northern Plains tribe. ${ }^{11}$ The RCT's enrollment goal was 600 AI caregiver-child 
dyads; enrollment began in September 2011 and was completed in February 2014. Each caregiver-child dyad is recruited when the child is a newborn and followed up until the child is 36 months old. The RCT has completed all intervention activities, and final follow-up assessments will be completed in early 2017 .

The CNOHR Study II, a cluster-RCT, enrolled children 3 to 5 years old in 52 Navajo Nation Head Start Programs. ${ }^{12}$ It tested whether an intervention of fluoride varnish (FV) administration and oral health promotion education in Head Start classrooms could reduce the number of decayed, missing, and filled primary tooth surfaces in children, as compared to children receiving usual care which included regular dental services provided by the Indian Health Service. Lay tribal members (Community Oral Health Specialists), who had received brief training from oral health and behavioral experts delivered the intervention. FV was offered up to four times/school year; oral health promotion education was provided to enrolled children (5 times/school year) and their caregivers (4 times/school year) in separate sessions for up to two years. Children were followed for up to three years. A total of 1,016 caregiver-child dyads were enrolled. This RCT has completed all data collection and the main outcome paper has been published. ${ }^{13}$

The CAN DO Glass Ionomer Fluoride Varnish Trial (GIFVT) RCT enrolled children aged 2.5 to 3 years, primarily Latinos, at two community health centers (CHCs) in San Diego County, California, to compare the caries prevention efficacy of FV applied every six months as compared to the combination of FV applied every six months and the annual application of fluoride-releasing glass ionomer sealants to the eligible occlusal surfaces of primary molar teeth. The primary outcomes include caries incidence and increment over 3 annual follow-up assessments. This RCT enrolled 597 participants, completed all intervention activities, and completed 36 month follow-up assessments in February 2016. ${ }^{14}$

The CREEDD Tooth Smart Healthy Start (TSHS) trial ${ }^{15}$, a cluster-RCT, enrolled motherchild dyads, with children aged 0 to 5 years, residing in public housing developments in the greater Boston area. The youngest eligible child was designated as the 'index' child, but study procedures were made available to all age-eligible children in the family. This report includes 1,065 dyads enrolled across 26 separate housing developments. The RCT compares two community-based multimodal interventions: (i) Motivational Interviewing (counseling) delivered to participating parents/legal guardians by dental health advocates (lay providers who were also mothers residing in public housing), child FV application, child oral health assessment, and referral to dental health services as needed; and (ii) written oral health education materials regarding ECC prevention, child FV application, child oral health assessment, and referral to dental health services as needed. All intervention components, including FV, are delivered quarterly for two years. The primary outcome is 2-year incidence of caries. This RCT is currently ongoing. The final 24-month outcome assessment on all participants is expected to be completed in November 2016.

All studies offered various levels and forms of compensation for attendance at study visits. The various retention strategies developed and implemented for each trial were summarized and tabulated. The observations made by each trial regarding their experiences with various strategies were categorized by their strengths and weaknesses and the strategies' 
effectiveness rated on a four-point scale $(\mathrm{A}=$ =xcellent; $\mathrm{B}=$ good; $\mathrm{C}=$ fair; $\mathrm{D}=$ poor) by each trial's staff.

\section{Recruitment and Follow-up}

Descriptive statistics were generated regarding numbers of enrolled participants, children and/or their caregivers, who did or did not return for scheduled study follow-up visits at the 12,24 , and 36 month study examination windows, as related to each RCT's protocol. The follow-up percentages at scheduled follow-up visits for each RCT were tabulated through December 2015 (“\% with follow-up"). Because three RCTs were still actively following participant dyads as of December 31, 2015, the calculation of each follow-up rate was restricted to dyads that already had been due for the corresponding follow-up visit. To convey the progress of each RCT for each follow-up visit, RCT summaries also include the percentage of dyads for which the time of scheduled visit had passed ("\% with visit window closed"). For each RCT, the summary statistics are based upon the sample that will be the focus of the trial's main outcome analyses.

\section{Results}

As of December 31, 2015, only one trial, CNOHR-II, had completed all data collection activities (Table 2). For the CNOHR-II study, over 50\% of eligible participants attended their 12, 24 and 36 month visits. The CNOHR-I study will complete all its scheduled 36 month visits in mid-2017. Through 2015, CNOHR-I participant attendance at the 12, 24 and 36 month visits has exceeded $80 \%$ (Table 2). Similarly, over $80 \%$ of eligible GIFVT participants attended their 12, 24 and 36 month visits. The TSHS study has achieved an over $70 \%$ attendance rate for its scheduled 12 and 24 month visits (Table 2).

\section{Project-specific Lessons Learned (Table 3)}

For both CNOHR studies, many challenges were related to working in remote and rural settings. Involving the community in the development of retention strategies and delivery of interventions was critical. The CNOHR-I Motivational Interventionists and the CNOHR-II Community Oral Health Specialists were all community members. They were familiar with local customs, the geography of each Reservation, spoke the local tribal language and were sensitive to the life-circumstances of study participants. These characteristics allowed them to recognize and meet the needs of study participants. ${ }^{16}$

Using the local media, including newspaper ads, billboards with oral health messages, and airing interviews with the study PI and field staff on the local tribal radio helped to spread the word and establish trust for CNOHR-I on the Reservation (Table 3a). Moreover, the field staff became recognized in the community as representatives of the study, and participants felt safe and comfortable having them in their homes. ${ }^{17}$ This rapport between the research staff and the community helped in retaining study participants and tracking participants who had been lost to follow-up.

For CNOHR-II, sending personalized letters was one of the most effective retention strategies. Other strategies (Table 3b) such as, telephone calls, text and email had varying success. ${ }^{17}$ In the final year of data collection, home visits were added that facilitated 
retaining participants as it was convenient for the participants and accommodated their work schedules. These visits, however, added to study costs.

GIFVT staff built upon knowledge from a previous study in the same community which focused on barrier reduction, incentives, and relationship building. ${ }^{18}$ GIFVT investigators found that having a community outreach specialist who either comes from the community or manages to integrate with the community helped build trust (Table 3c). In order to integrate with the community, the outreach specialist and the rest of the study team should not only be able to communicate in the predominant language (in GIFVT's case, Spanish) but also be familiar with the culture that forms the community. While in GIFVT most participants were of Mexican origin, the study composition varied from families who had just arrived in the United States with a first language of Spanish, to families who have lived in the U.S. for several decades with communication mainly in English, and who may have a separate culture within the community.

Creating a family and child-friendly space in the Community Health Center (CHC) dental home, as done in a prior study ${ }^{18}$, made families more comfortable and encouraged them to attend study visits. For example, an office with toys for siblings and participants, and with enough room to store strollers made parents feel welcomed. In addition, having diapers at the $\mathrm{CHC}$ and other items needed to care for children may have positively impacted attendance. Furthermore, having staff who can naturally and comfortably interact with toddlers was an asset to GIFVT (e.g., genuinely speak to children about the latest cartoon characters, movies, toys).

Finally, after assessing community patterns of attendance by using historical data ${ }^{18}$, the study team was able to anticipate broken appointments, and hence add several tools to stay in contact with the families, such as telephone calls and postcards, and by also reaching out to secondary and tertiary contacts. In a context where pre-paid mobile phones are normative, the team had to find alternative ways to stay in contact with participants with expired mobile phone minutes or changed phone numbers.

Building trust within community was also key to retention for the TSHS RCT. The community includes the participant population, the management staff at the Boston Housing Authority (BHA) sites, and the tenant task force groups. The majority of the TSHS staff were bilingual and were current or previous residents of the BHA sites, which allowed them to relate to the participants and develop rapport. TSHS staff were individually assigned to BHA sites and each endeavored to build relationships between the research project and that particular site. This promoted BHA's trust in participating in research, and staff members felt comfortable conducting home visits for those who were difficult to reach by phone, text or email. Many times staff members had been to the participant's home before and knew the best time of day to reach her. Over time, staff members began to ascertain the best days and times to reach participants, and would often travel to their homes during these times to conduct surveys or counseling for participants who were difficult to reach using other methods. 
To further build trust with the community, including the management offices and tenant task force groups, the TSHS team became actively engaged with the community. For example, each summer the team would participate in "Back-to-School" events at the different sites by setting up "Tooth Smart Healthy Start" booths and creating activities for the children.

Additionally, the coordinators and other staff members attended community meetings to give updates on the progress of the study. To acknowledge the hard work and assistance of BHA management staff, TSHS put together holiday gifts each year and personally delivered them to the sites.

Throughout the TSHS RCT, post cards were mailed, and also left at participants' homes by staff members for those participants who were unable to be reached to schedule appointments or who were not home at the time of a scheduled visit. The post cards were developed in a way that allowed the team to personalize each post card with a handwritten note in the participant's language of preference. The post cards highlighted the visit type for each participant (e.g., assessment or counseling) and whether she would be receiving a gift card after completion. Additionally, this method of retention via postal service allowed TSHS to identify when a participant had moved from her current residence, as the post card would be returned to the office.

The most effective approach to retention for TSHS was the Community Outreach Specialist position, which was created in the latter half of the RCT. This bilingual specialist's time was entirely devoted to contacting and conducting study visits with hard-to-reach participants. The methods used by the specialist included going to the housing site at different times throughout the week, such as weekends and evenings, speaking with the management office regarding participants who relocated, and calling numbers that were previously not working. The Community Outreach Specialist was someone who was skilled in effectively communicating with participants who were considering leaving the study or who had missed multiple study visits. A main focus for the position was on having participants complete their final study visit. This effort resulted in improved attendance at the final 24-month visit over the interim 12-month visit.

\section{Discussion}

Our findings illustrate the successes and challenges with using a variety of retention methods that are common to other longitudinal research, namely mailings, phone calls and text messaging, and compensation. Mailings included four main types of contacts: use of birthday or holiday cards, reminders for scheduled visits, check-ins for participants who missed several visits, and notifying the community regarding staff presence in the area and data collection times. Overall, mailings were beneficial, especially for participants who were hard-to-reach by other means of communication or for identifying participants that had moved from their addresses on file, a strategy commonly employed by others. ${ }^{18,19}$ Mailings were easy to implement and required few resources; however, there is difficulty in quantifying the effectiveness of mailings such as birthday or holiday cards. Also, while identification of outdated addresses might provide valuable information for the research team, it may not overcome the challenge of reaching participants. 
Extensive contact has been shown to improve retention in studies with demanding protocols ${ }^{18,20}$, with two common methods being use of phone calls and text messaging. Phone calls provided valuable opportunities to have consistent contact with participants. However, challenges included phone services being disconnected or calls not being answered. Some participants preferred text messages, consistent with research showing that texting is particularly useful for tracking and contacting hard-to-reach populations. ${ }^{21}$ Possible reasons for preferring texting could include the ubiquity of cellular phones, the less-obtrusive aspect of texting as opposed to voice calls, and possible lower costs of cellular phone texts versus voice communications especially for cellular plans with unlimited texting. This preference could be easily honored early on by including a "best way of contacting" item to enrollment forms, a strategy suggested by a Navajo nation Community Advisory Board (CAB) ${ }^{22}$ Barriers still remain, such as poor cellphone reception (particularly in rural areas), lack of cellphone minutes or data, and changing cellphone numbers. ${ }^{22}$

Compensation has been shown to improve retention, particularly when payments are higher and in cash, but perceived coercion ${ }^{18,23}$ is an important consideration. ${ }^{24}$ Cash compensation may be used more often by participants to purchase essentials ${ }^{23}$. Gift cards, depending on the vendor, may also be useful for purchase of essentials. However, monetary compensation may not be a critical motivator for all participants across a population, especially those studied here, who face multiple obstacles to attending visits. Similar to other findings, while compensation has some impact, it is difficult to quantify and may have differential impact across participants and studies. ${ }^{25}$ As further noted by Abernethy et al. ${ }^{25}$, compensation is closely related to issues of access to care and disparities in care. In that regard, retention may be high in studies that provide intervention services that study participants highly value. ${ }^{26}$ This may be true for the provision of FV to all children in TSHS and for the use of glass ionomer sealants in GIFVT. As such sealants are not the usual standard of care for primary teeth, families may have felt motivated by receiving this extra treatment at no cost.

While various common methods were used, these four studies also had to pay particular attention to the communities with whom they worked in order to have successful retention. This community engagement included attendance at community activities and the use of CABs, which were required by the NIDCR funding mechanism supporting these centers. CABs have been used previously for retention among American Indian populations for behavioral interventions to reduce $\mathrm{ECC}^{16}$, and $\mathrm{CNOHR}$ continued to use them while opening up $\mathrm{CAB}$ meetings to family members. This allowed for more feedback from community members and also created respectful relationships with families, which has also been shown to increase retention. ${ }^{26}$

Most importantly, successful retention was aided by creating rapport with the community. Retention strategies are most effective when there is a sense of trust between participants and study staff ${ }^{18,27}$, and strategies for retention must involve the entire community. ${ }^{28}$ These four studies used a variety of means for community engagement tailored to the target population. Activities included community-wide celebrations, holiday parties, health fairs, and meetings at local community gathering places, such as tribal Chapter Houses. 
Approaches used paid particular attention to cultural sensitivity, in order to establish valuable cultural connections. ${ }^{29}$ For example, cultural sensitivity in the Latino communities may mean incorporating family as part of recruitment, showing respect by using formal titles and listening carefully, and having interactions that are warm and personal. ${ }^{18,} 30$ The GIFVT study demonstrated this by focusing on personalismo and familismo, both of which were population-specific values that helped to establish rapport between staff and participants. ${ }^{18}$ Bilingual staff, in particular, are crucial to increasing retention ${ }^{18,28,31}$, and both GIFVT and TSHS studies made efforts to hire staff who were bilingual and bicultural in order to increase staff-participant rapport. However, there were challenges to this. Finding bilingual/ bicultural individuals with adequate qualifications was challenging, though mediated by a number of strategies, such as extensive training and close supervision in early stages of the studies. Despite these strategies, staff turnover and absenteeism were common challenges.

Our findings, while novel and potentially important, have several limitations. This report represents a "case series" of observations made by four distinct RCTs. None of these RCTs formally tested or directly compared different retention strategies, as such work was beyond the focused scope of each RCT. The findings reported on each RCT's retention strategies, while collected systematically, are not experimentally based and are essentially anecdotal in nature. In addition, each trial focused on particular populations that varied greatly among the four RCTs in the race/ethnicity of participants and in their geographic settings.

Nevertheless, these observations may be useful in guiding the design of future RCTs and identifying promising research questions for systematic investigation in disparities populations. For example, future research could include exploring how health behavior theory constructs operate within the realm of retention and whether certain theoretical constructs are more or less predictive of participant retention. Approaches could follow the work of Spoth and Redmond ${ }^{32}$ on how constructs of the Health Belief Model are weighted differently in predicting a behavioral outcome, while also taking into account context features that may simultaneously influence beliefs. ${ }^{32}$ For the purpose of studies like ours in the EC4, the intended behavioral outcome is ongoing participation, i.e., retention. Analysis of retention methods' effectiveness could apply Spoth and Redmond ${ }^{32}$ in two primary ways: (a) studies could focus on the interrelationship of various constructs of social behavioral theories, such as the Health Belief Model, and how constructs affect each other and ultimately predict the intended outcome, while (b) noting relevant participant characteristics unique to each hard-to-reach study population and describing the effect of the context on health behavior theory constructs. Future studies, in their formative phase, could include collection of in-depth baseline data from participants regarding various constructs, e.g., perceived susceptibility. After studying the relative predictive value of each construct, findings could be used to inform how to best achieve retention with methods that reflect the most salient predictive constructs in their chosen population.

In conclusion, improving efforts to recruit and retain hard-to-reach populations will improve the rigor, quality and efficiency of intervention studies aimed at reducing oral health disparities. An increase in this evidence base is necessary for improving oral health outcomes. Our findings may help to guide research teams on how to better design future 
RCTs in order to maximize retention of study participants and yield needed data on effective interventions to reduce oral health disparities.

\section{Acknowledgments}

This research was supported by the National Institute of Dental and Craniofacial Research, National Institutes of Health, under cooperative agreements U54 DE019259, U54 DE019285, and U54 DE019275. The content of this report is solely the responsibility of the authors and does not necessarily represent the official views of the National Institutes of Health or of the awardee institutions. A complete list of EC4 members is available at www.oralhealthdisparities.org. We gratefully acknowledge the many critical contributions made to this work by the NIDCR Program Official for the EC4, Dr. Ruth Nowjack-Raymer. We would also like to thank all the children, their families and communities that took part in the studies described.

\section{References}

1. Bonevski B, Randell M, Paul C, Chapman K, Twyman L, Bryant J, et al. Reaching the hard-toreach: a systematic review of strategies for improving health and medical research with socially disadvantaged groups. BMC Med Res Methodol. 2014; 14:42.doi: 10.1186/1471-2288-14-42 [PubMed: 24669751]

2. Stoy DB, Curtis RC, Dameworth KS, Dowdy AA, Hegland J, Levin JA, et al. The successful recruitment of elderly black subjects in a clinical trial: the CRISP experience. Cholesterol Reduction in Seniors Program. J Natl Med Assoc. 1995; 87(4):280-287. [PubMed: 7752281]

3. Blumenthal DS, Sung J, Coates R, Williams J, Liff J. Recruitment and retention of subjects for a longitudinal cancer prevention study in an inner-city black community. Health Serv Res. 1995; 30(1 Pt 2):197-205. [PubMed: 7721592]

4. Gwadz M, Cleland CM, Hagan H, Jenness S, Kutnick A, Leonard NR, et al. Strategies to uncover undiagnosed HIV infection among heterosexuals at high risk and link them to HIV care with high retention: a "seek, test, treat, and retain" study. BMC Public Health. 2015; 15:481.doi: 10.1186/ s12889-015-1816-0 [PubMed: 25958200]

5. Spoont MR, Nelson DB, Murdoch M, Sayer NA, Nugent S, Rector T, et al. Are there racial/ethnic disparities in VA PTSD treatment retention? Depress Anxiety. 2015; 32(6):415-425. DOI: 10.1002/da.22295 [PubMed: 25421265]

6. Lewis-Fernández R, Balán IC, Patel SR, Sánchez-Lacay JA, Alfonso C, Gorritz M, et al. Impact of motivational pharmacotherapy on treatment retention among depressed Latinos. Psychiatry. 2013; 76(3):210-222. DOI: 10.1521/psyc.2013.76.3.210 [PubMed: 23965261]

7. Myers K, Vander Stoep A, Lobdell C. Feasibility of conducting a randomized controlled trial of telemental health with children diagnosed with attention-deficit/hyperactivity disorder in underserved communities. J Child Adolesc Psychopharmacol. 2013; 23(6):372-378. DOI: 10.1089/ cap.2013.0020 [PubMed: 23952183]

8. Odierna DH, Schmidt LA. The effects of failing to include hard-to-reach respondents in longitudinal surveys. Am J Public Health. 2009; 99(8):1515-1521. DOI: 10.2105/AJPH.2007.111138 [PubMed: 19008525]

9. Burchard EG, Oh SS, Foreman MG, Celedón JC. Moving toward true inclusion of racial/ethnic minorities in federally funded studies. A key step for achieving respiratory health equality in the United States. Am J Respir Crit Care Med. 2015; 191(5):514-521. DOI: 10.1164/rccm. 201410-1944PP [PubMed: 25584658]

10. Tiwari T, Casciello A, Gansky SA, Henshaw M, Ramos-Gomez F, Rasmussen M, et al. Recruitment for health disparities preventive intervention trials: the early childhood caries collaborating centers. Prev Chronic Dis. 2014; 11:E133.doi: 10.5888/pcd11.140140 [PubMed: 25101490]

11. Batliner T, Fehringer KA, Tiwari T, Henderson WG, Wilson A, Brega A, et al. Motivational interviewing with American Indian mothers to prevent early childhood caries: study design and methodology of a randomized control trial. Trials. 2014; 15125(1):16. [PubMed: 24405891] 
12. Quissell DO, Bryant LL, Braun PA, Cudeii D, Johs N, Smith V, et al. Preventing caries in preschoolers: an innovative community-based clinical trial in Navajo Nation Head Start programs. Contemp Clin Trials. 2014; 37(2):242-51. [PubMed: 24469238]

13. Braun PA, Quissell DO, Henderson WG, Bryant LL, Gregorich SE, George C, et al. A ClusterRandomized, Community-Based, Tribally Delivered Oral Health Promotion Trial in Navajo Head Start Children. J Dent Res. 2016; :1-6. DOI: 10.1177/0022034516658612

14. Ramos-Gomez F, Gregorich SE, Chaffee B, Cheng J, Cheng NF, Featherstone J, et al. Glass Ionomer and Fluoride Varnish Trial (GIFVT): A Randomized Clinical Trial of Sealants on Primary Molars to Prevent Early Childhood Caries (unpublished observations).

15. ClinicalTrials.gov, NCT01205971; clinicaltrials.gov/ct2/show/NCT01205971 Accessed July 29, 2016.

16. Tiwari T, Sharma T, Harper M, Zacher T, Roan R, George C, et al. Community Based Participatory Research to Reduce Oral Health Disparities in American Indian Children. Journal of Family Medicine. 2015; 2(3)

17. Tiwari T, Albino J, Batliner TS. Challenges Faced in Engaging American Indian Mothers in an Early Childhood Caries Preventive Trial. International Journal of Dentistry. 20152015 May 5.

18. Ramos-Gomez F, Chung LH, Gonzalez Beristain R, Santo W, Jue B, Weintraub J, et al. Recruiting and retaining pregnant women from a community health center at the US-Mexico border for the Mothers and Youth Access clinical trial. Clinical Trials. 2008; 5:336-346. [PubMed: 18697848]

19. Lindenberg CS, Solorzano RM, Vilaro FM, Westbrook LO. Challenges and strategies for conducting intervention research with culturally diverse populations. J Transcult Nurs Off J Transcult Nurs Soc Transcult Nurs Soc. 2001; 12(2):132-139.

20. Escobar-Chaves SL, Tortolero SR, Mâsse LC, Watson KB, Fulton JE. Recruiting and retaining minority women: findings from the Women on the Move study. Ethn Dis. 2002; 12(2):242-251. [PubMed: 12019934]

21. Maher JE, Pranian K, Drach L, Rumptz M, Casciato C, Guernsey J. Using text messaging to contact difficult-to-reach study participants. Am J Public Health. 2010; 100(6):969-970. author reply 970. DOI: 10.2105/AJPH.2009.188391 [PubMed: 20395564]

22. Bryant LL, Quissell DO, Braun PA, Henderson WG, Johs N, George C, et al. A Community-Based Oral Health Intervention in Navajo Nation Head Start: Participation Factors and Contextual Challenges. J Community Health. Oct.2015 doi: 10.1007/s10900-015-0102-5

23. Festinger DS, Marlowe DB, Dugosh KL, Croft JR, Arabia PL. Higher magnitude cash payments improve research follow-up rates without increasing drug use or perceived coercion. Drug Alcohol Depend. 2008; 96(1-2):128-135. DOI: 10.1016/j.drugalcdep.2008.02.007 [PubMed: 18395365]

24. U.S. Food and Drug Administration. Payment to Research Subjects - Information Sheet. http:// www.fda.gov/RegulatoryInformation/Guidances/ucm126429.htm. Accessed July 29, 2016

25. Abernethy, AP., Allen Lapointe, NM., Wheeler, JL., Irvine, RJ., Patwardhan, M., Matchar, D. Horizon Scan: To What Extent Do Changes in Third-Party Payment Affect Clinical Trials and the Evidence Base?. Rockville (MD): Agency for Healthcare Research and Quality (US); 2009. http:// www.ncbi.nlm.nih.gov/books/NBK284762/. Accessed July 29, 2016

26. Webb DA, Coyne JC, Goldenberg RL, Hogan VK, Elo IT, Bloch JR, et al. Recruitment and retention of women in a large randomized control trial to reduce repeat preterm births: the Philadelphia Collaborative Preterm Prevention Project. BMC Med Res Methodol. 2010; 10:88.doi: 10.1186/1471-2288-10-88 [PubMed: 20920265]

27. Burns D, Soward ACM, Skelly AH, Leeman J, Carlson J. Effective recruitment and retention strategies for older members of rural minorities. Diabetes Educ. 2008; 34(6):1045-1052. DOI: 10.1177/0145721708325764 [PubMed: 19075086]

28. Eakin EG, Bull SS, Riley K, Reeves MM, Gutierrez S, McLaughlin P. Recruitment and retention of Latinos in a primary care-based physical activity and diet trial: The Resources for Health study. Health Educ Res. 2007; 22(3):361-371. DOI: 10.1093/her/cyl095 [PubMed: 16963726]

29. Williams KP, Ford S, Meghea C. Cultural Connections: the Key to Retention of Black, Latina, and Arab Women in the Kin Keeper(SM) Cancer Prevention Intervention Studies. J Cancer Educ Off J Am Assoc Cancer Educ. Jul.2015 doi: 10.1007/s13187-015-0857-5 
30. Miranda J, Azocar F, Organista KC, Muñoz RF, Lieberman A. Recruiting and retaining lowincome Latinos in psychotherapy research. J Consult Clin Psychol. 1996; 64(5):868-874. [PubMed: 8916613]

31. McMillan B, Green JM, Woolridge MW, Dyson L, Renfrew MJ, Clarke GP. Studying the infant feeding intentions of pregnant women experiencing material deprivation: methodology of the Looking at Infant Feeding Today (LIFT) study. Soc Sci Med 1982. 2009; 68(5):845-849. DOI: 10.1016/j.socscimed.2008.12.032

32. Spoth R, Redmond C. Parent motivation to enroll in parenting skills programs: A model of family context and health belief predictors. J Fam Psychol. 1995; 9(3):294-310. DOI: 10.1037/0893-3200.9.3.294 


\section{Table 1}

Randomized Controlled Trials Conducted by the Early Childhood Caries Collaborating Centers

\begin{tabular}{|c|c|c|}
\hline ClinicalTrials.gov NCT & Principal Investigators & Study Title \\
\hline NCT01116726 ${ }^{11}$ & Terrence Batliner, DDS, MBA & $\begin{array}{l}\text { CNOHR-I: Promoting Behavioral Change for Oral Health in } \\
\text { American Indian Mothers and Children }\end{array}$ \\
\hline NCT01116739 12,13 & $\begin{array}{l}\text { Patricia Braun, MD, MPH } \\
\text { David Quissell, PhD }\end{array}$ & $\begin{array}{l}\text { CNOHR-II: Preventing Caries in Preschoolers: Testing a Unique } \\
\text { Service Delivery Model in American Indian Head Start Programs }\end{array}$ \\
\hline NCT01129440 14 & $\begin{array}{l}\text { Stuart Gansky, DrPH } \\
\text { Francisco Ramos-Gomez, DDS, MS, MPH }\end{array}$ & $\begin{array}{l}\text { GIFVT: Glass Ionomer Sealant and Fluoride Varnish Trial to Prevent } \\
\text { Early Childhood Caries }\end{array}$ \\
\hline NCT01205971 15 & $\begin{array}{l}\text { Michelle Henshaw, DDS, MPH, } \\
\text { Belinda Borrelli, PhD }\end{array}$ & $\begin{array}{l}\text { TSHS: Tooth Smart Healthy Start: Oral Health Advocates in Public } \\
\text { Housing }\end{array}$ \\
\hline
\end{tabular}




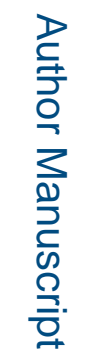

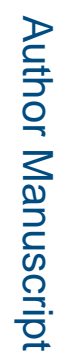

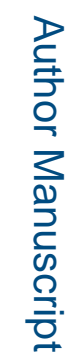

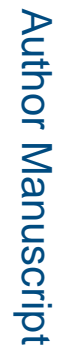

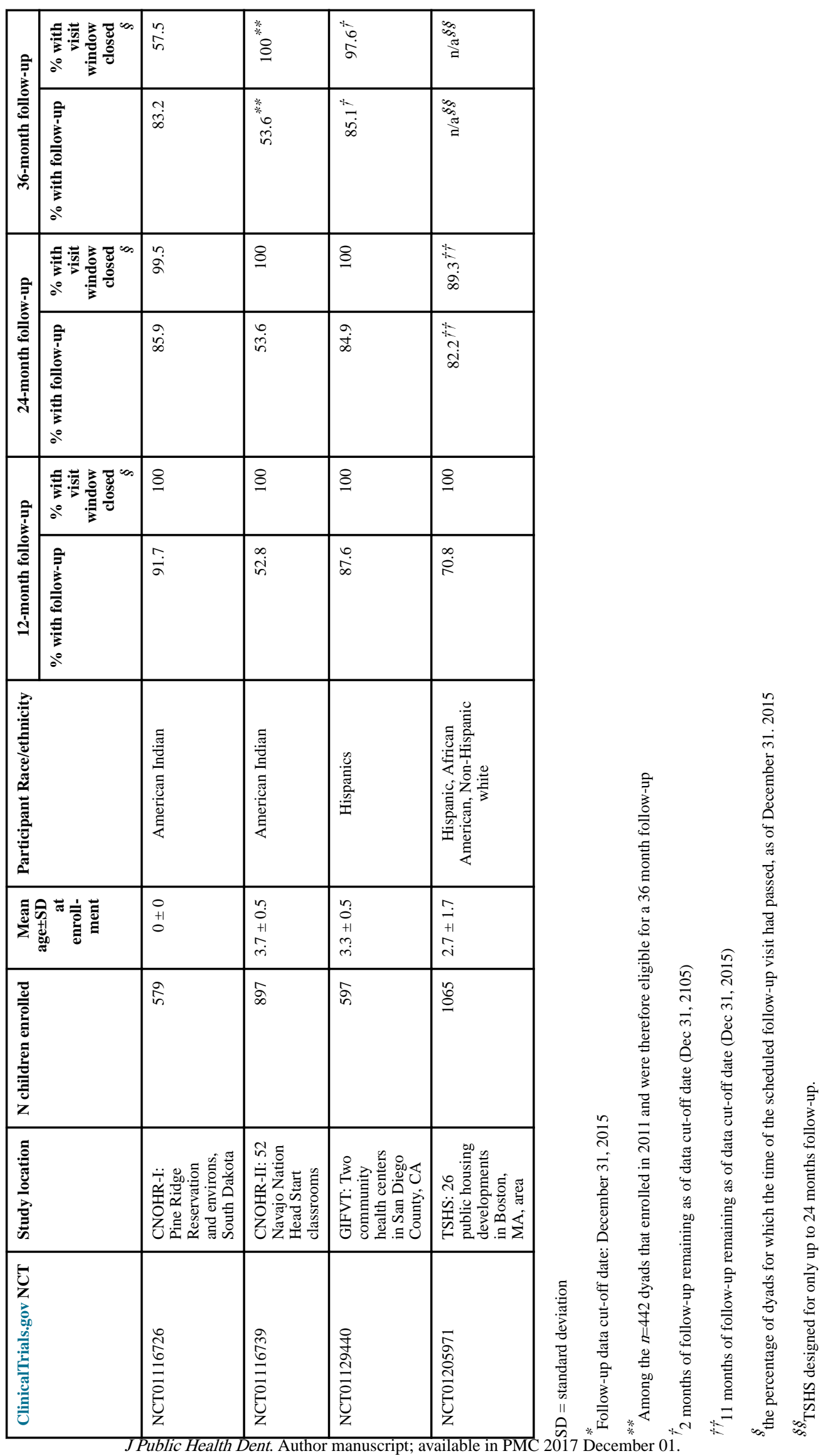




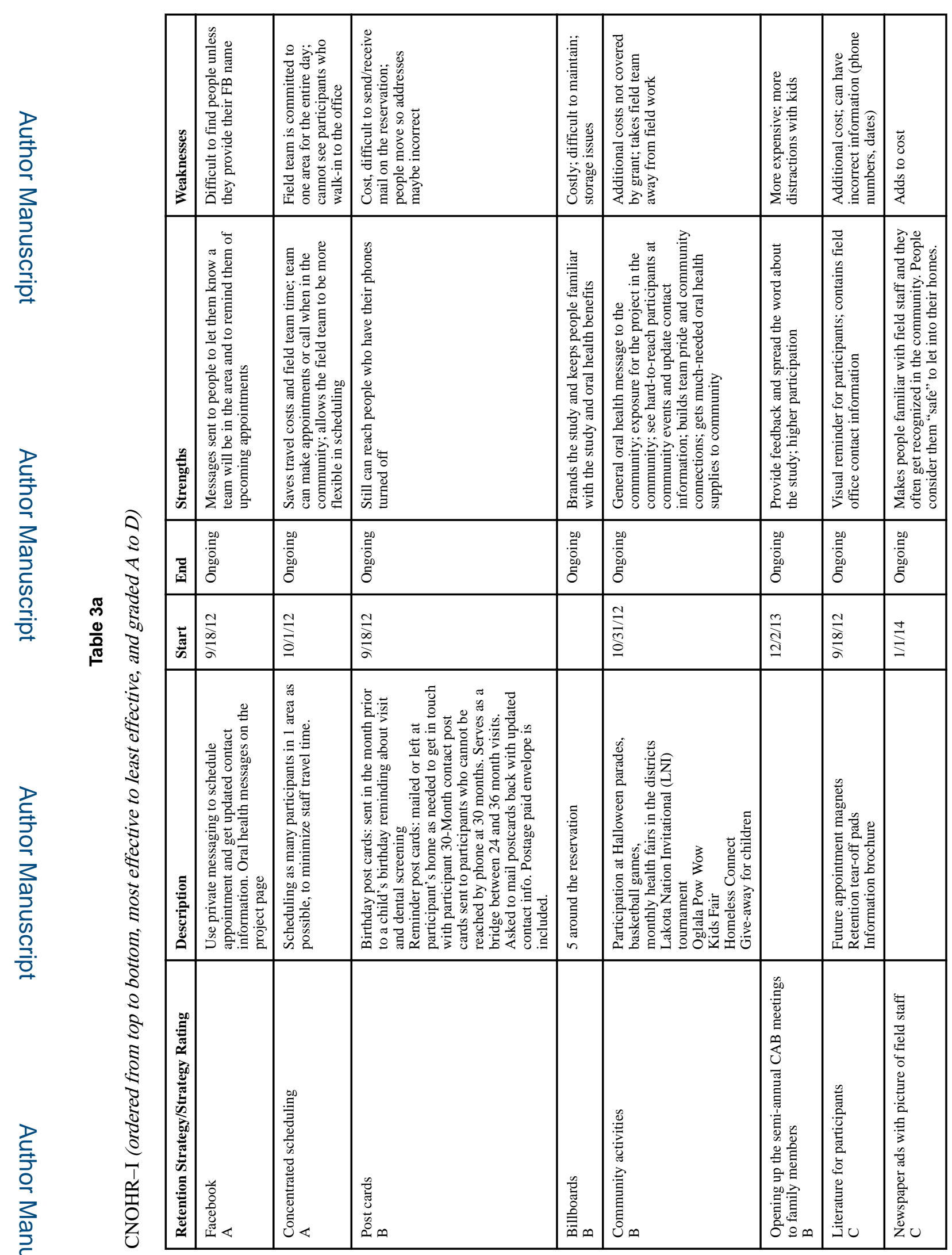

J Public Health Dent. Author manuscript; available in PMC 2017 December 01. 


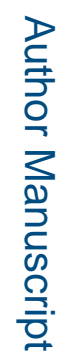

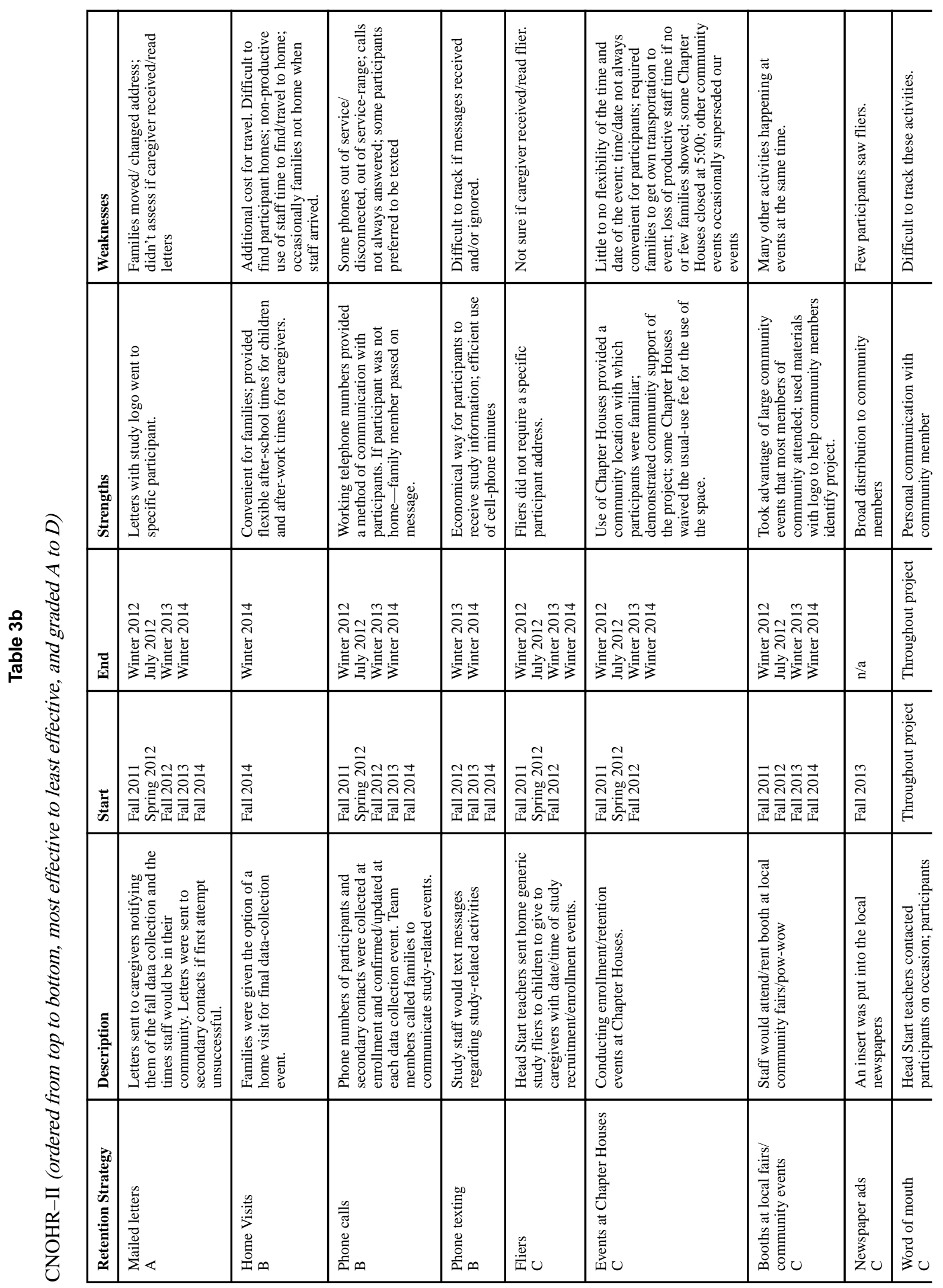

J Public Health Dent. Author manuscript; available in PMC 2017 December 01. 


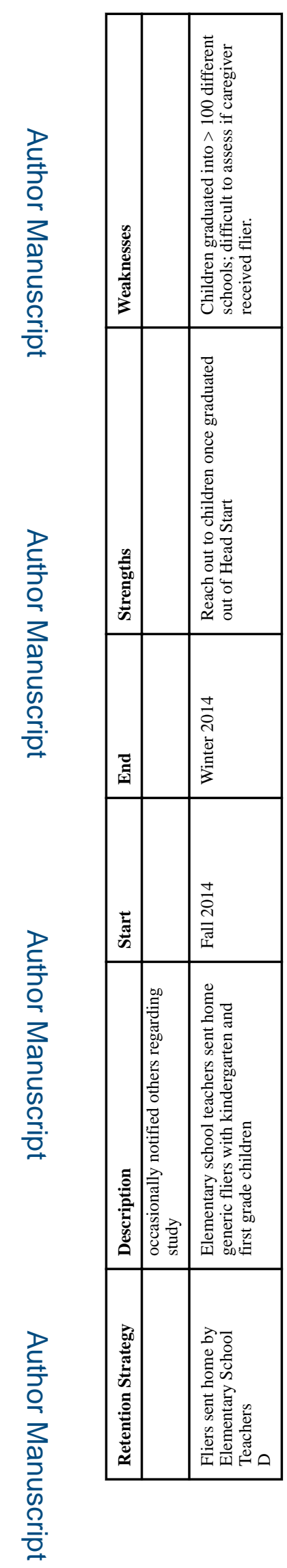




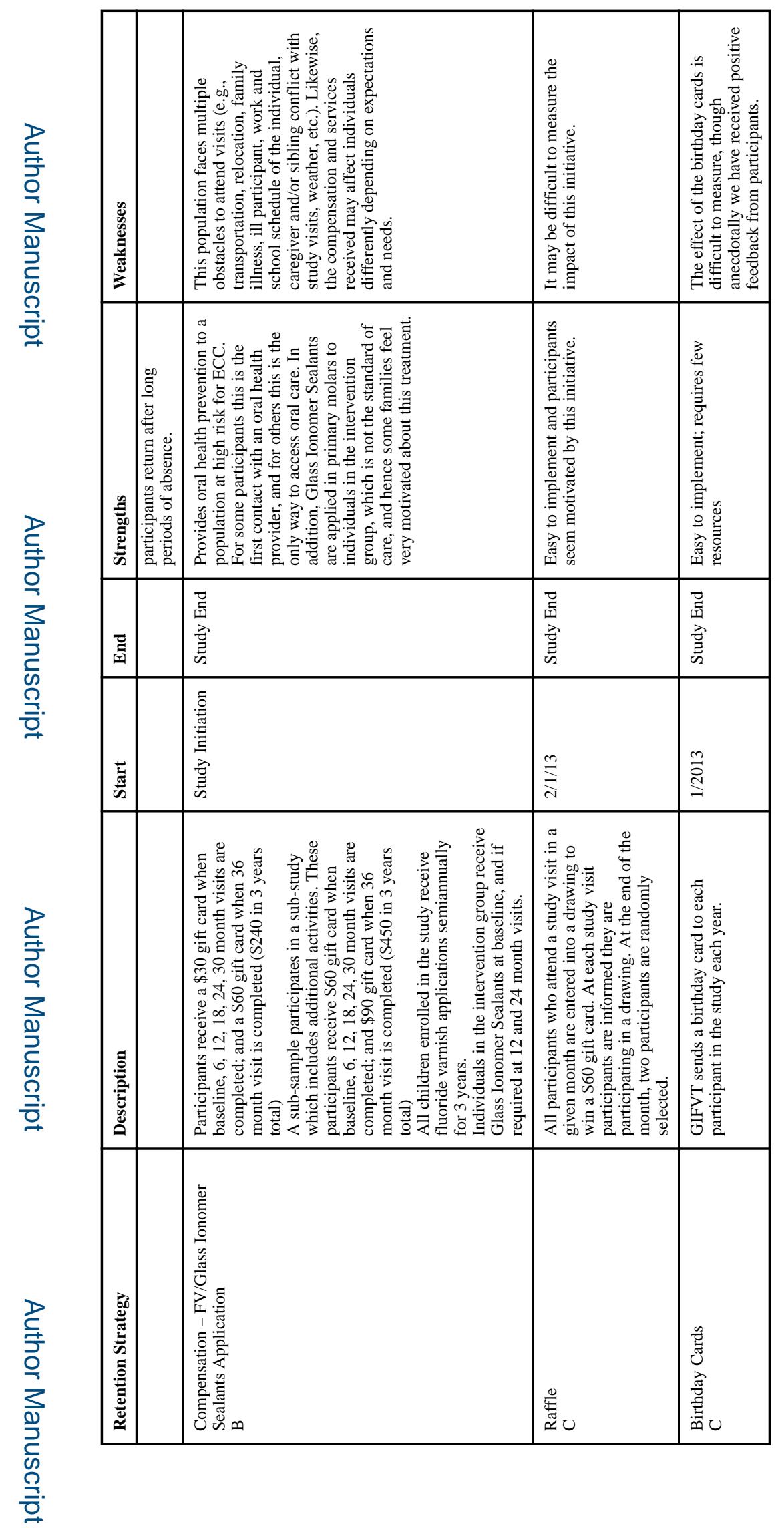

J Public Health Dent. Author manuscript; available in PMC 2017 December 01. 


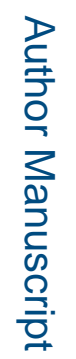

\begin{tabular}{|c|c|c|c|c|c|c|}
\hline 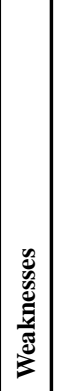 & 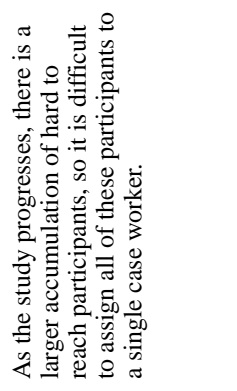 & 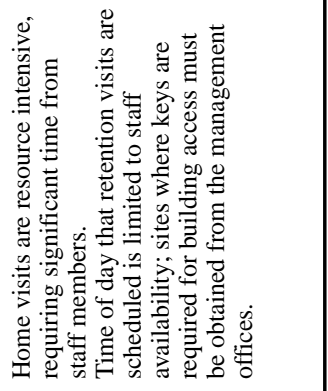 & 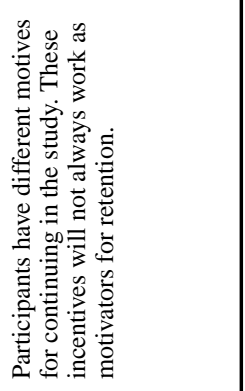 & 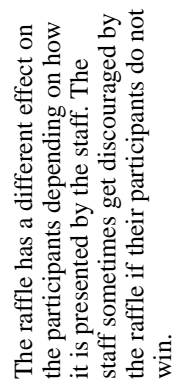 & & 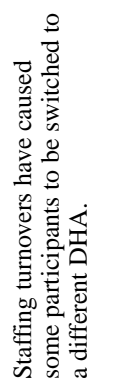 \\
\hline 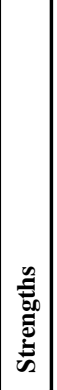 & 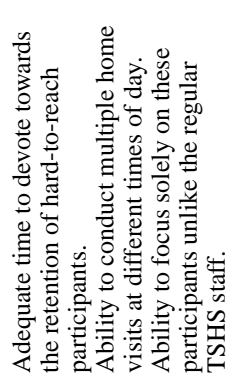 & 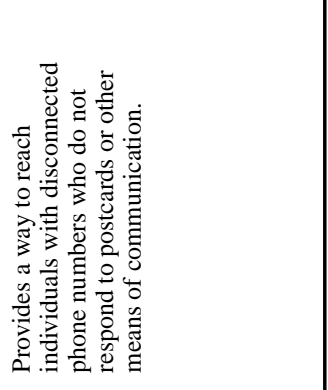 & 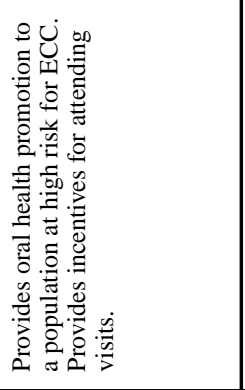 & 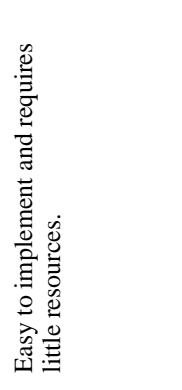 & 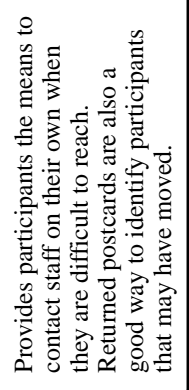 & 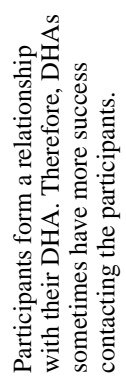 \\
\hline $\begin{array}{l}\mathbf{\Xi} \\
\mathbf{a}\end{array}$ & 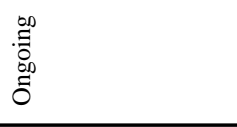 & 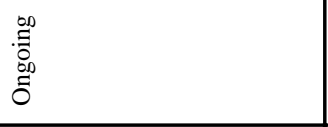 & 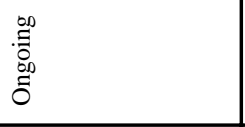 & 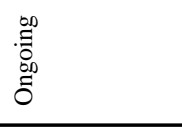 & 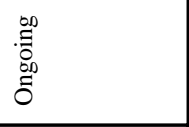 & 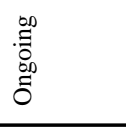 \\
\hline 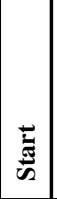 & 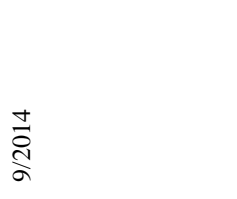 & 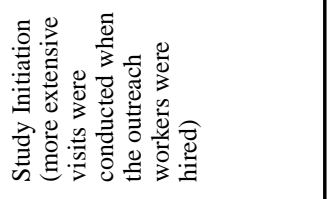 & 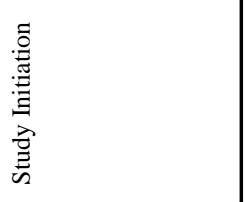 & 离 & 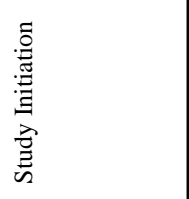 & 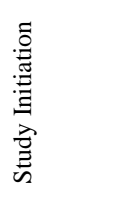 \\
\hline 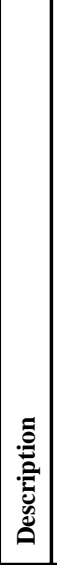 & 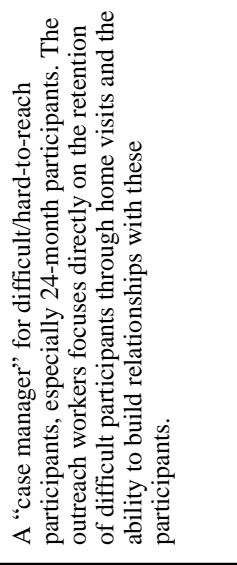 & 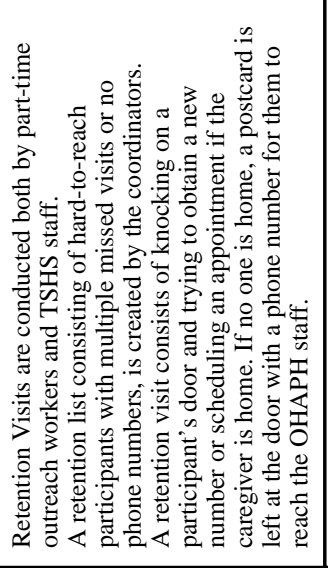 & 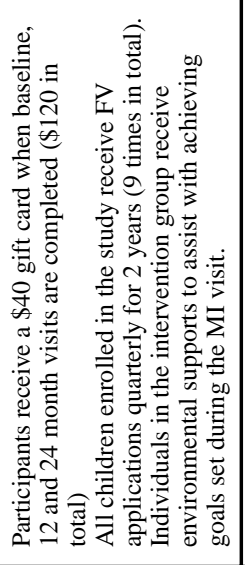 & 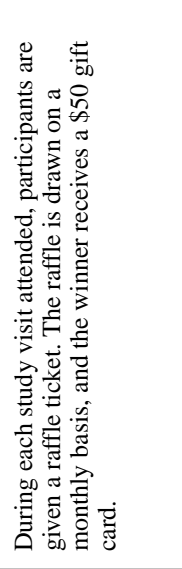 & 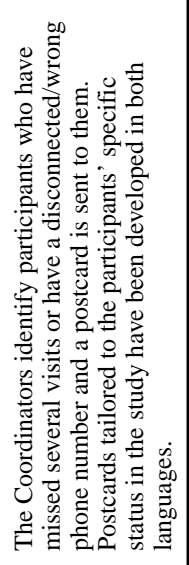 & 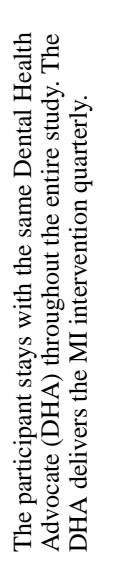 \\
\hline 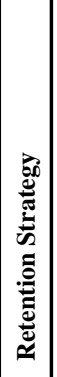 & 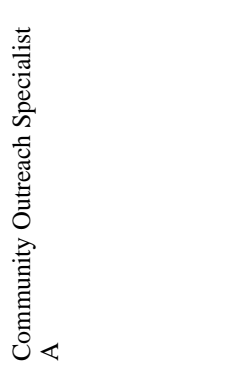 & 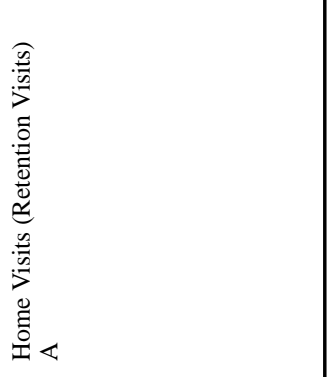 & 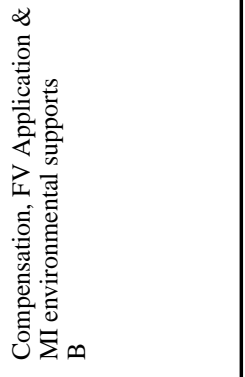 & $\approx$ & 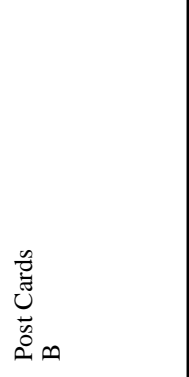 & 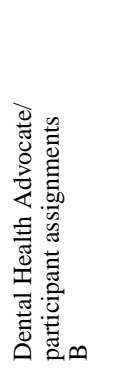 \\
\hline
\end{tabular}

J Public Health Dent. Author manuscript; available in PMC 2017 December 01. 


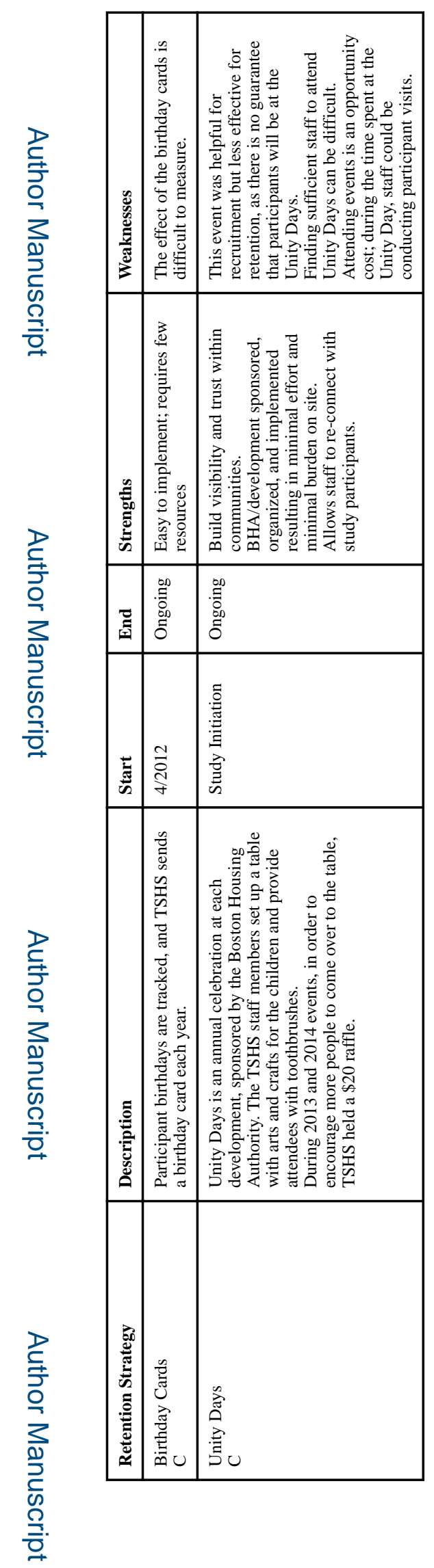

J Public Health Dent. Author manuscript; available in PMC 2017 December 01. 